\title{
Setting economic priorities for patient safety programs and patient safety research using case mix costing data
} T Jackson*1, HS Nghiem ${ }^{1}$, D Rowell ${ }^{1}$, C Jorm ${ }^{2}$ and J Wakefield ${ }^{3}$

\author{
Address: ${ }^{1}$ Australian Centre for Economic Research on Health, University of Queensland, Herston QLD, Queensland, Australia, ${ }^{2}$ Australian \\ Commission on Safety and Quality in Health Care, Department of Health \& Ageing, Sydney, New South Wales, Australia and ${ }^{3}$ Queensland Health \\ Patient Safety Centre, Queensland Health, Brisbane, Queensland, Australia \\ * Corresponding author
}

from 25th Patient Classification Systems International (PCSI) Working Conference

Fukuoka, Japan. II-I4 November 2009

Published: 5 November 2009

BMC Health Services Research 2009, 9(Suppl I):A4 doi:I0.1 186/1472-6963-9-SI-A4

This abstract is available from: http://www.biomedcentral.com/I472-6963/9/SI/A4

(c) 2009 Jackson et al; licensee BioMed Central Ltd.

\section{Introduction}

Patient safety efforts are often recommended solely on judgments about the relative importance of particular adverse events in hospital care, without considering the frequency and costs of all hospital-acquired illness and injury. The objective of the study was to use patient-level cost data to estimate relative economic priorities for hospital inpatient safety efforts.

\section{Methods}

Patient level costs are estimated using computerized patient costing systems that initially log individual utilization of inpatient services, and then apply sophisticated cost estimates from the hospital's general ledger. The occurrence of a hospital-acquired diagnosis is identified using a new Australian 'condition-onset' flag for all diagnoses not present on admission. These diagnoses are grouped to yield a comprehensive set of 144 categories of hospital-acquired conditions, using a recently-developed algorithm to summarize data coded with ICD-10-AM.

Standard linear regression techniques are used to identify the independent contribution to inpatient costs of hospital-acquired conditions, taking into account the case mix of a sample of acute inpatients $(\mathrm{n}=1,699,997)$ treated in Australian public hospitals in Victoria (2005/06) and Queensland (2006/07).

\section{Results}

The most costly types of adverse events were post-procedure endocrine and metabolic disorders, adding \$A 21,869 to the cost of an episode, followed by (methicillinresistant staphylococcus aureus) MRSA (+\$A 19,892) and enterocolitis due to Clostridium difficile (+\$A 19,745). Aggregate additional costs to the system were highest for septicaemia (+\$A 41.5 mil), complications of cardiac and vascular implants other than septicaemia (+\$A $28.7 \mathrm{mil})$, acute lower respiratory infections -- including influenza and pneumonia (\$A $28.0 \mathrm{mil}$ ) -- and UTI (+\$A $24.7 \mathrm{mil}$ ). Hospital acquired complications are estimated to add $17.1 \%$ to the costs of treatment in this sample.

\section{Conclusion}

Patient safety efforts frequently focus on dramatic but rare complications with very serious patient harms. Adding an economic dimension to priority-setting could result in changes to the priorities of patient safety programs. It could also provide guidance as to other areas where research into causes and prevention strategies may prove a productive investment. Financial information should be combined with information on patient harms to allow for cost-utility evaluation of future programs. 